\title{
The conclusions from TOE (theory of everything)
}

\section{Commentary}

In 1887, Heinrich Hertz observed the external photoelectric effect and the production and reception of electromagnetic waves. ${ }^{1}$ In 1888-1890, the photoelectric system was studied by the physicist lexander Stoletov. ${ }^{2-7}$ In 1900, Planck proposed a formula with a constant (subsequently called the Planck constant). ${ }^{8}$ The photoelectric effect was explained in 1905 by Albert Einstein. ${ }^{9}$ In TOE $^{10}$ is given description about 33 standard gravitational constants. If the Planck constant defines the boundary between the macrocosm, where the laws of Newton's mechanics operate, and the micro world, where the laws of quantum mechanics operate. Then it shall be also 33 boundaries between the macrocosm and the micro world and therefore 33 Planck constants. The number of the photoelectric effects shall be also 33 . E.g. for the external photo effect, internal photo effect and ventilated photoelectric effect. Of course, the speed of the light (photons) must also be different and not constant, because the conditions the temperature, gravity, and electromagnetic field on others differ celestial bodies are other. The values of 33 Planck constants and 33 photoelectric effect will be approximately equal to a value of 33 standard gravitational constants.

\section{The treatment with mini- and hyper-gravity}

Micro-and macro-organisms on the planet Earth evolve under the influence of electromagnetic ${ }^{11}$ and gravitational forces. ${ }^{12}$ The treatment with mini gravity should be effective and without the side effect. If do not abuse. With mini gravity can cells ${ }^{13}$ become larger, but their division will be slowly and with macro gravity can cells become smaller, and their division will be faster. It is can be helpful by choosing of the method of treatment with mini gravitation and hyper gravitation. The method can not treat injuries and urgent surgical operation! The treatment with a mini-gravity can begin by $1\left(\mathrm{Nm}^{2} \mathrm{~kg}^{-2}\right)$ and ends by $6,67\left(\mathrm{Nm}^{2} \mathrm{~kg}^{-2}\right)$. The treatment with hyper gravitation can begin by $6,67\left(\mathrm{Nm}^{2} \mathrm{~kg}^{-2}\right)$ and ends by $11\left(\mathrm{Nm}^{2} \mathrm{~kg}^{-2}\right)$. The dates are obtained by subtracting the gravitational constants. Of course this is only my advice for doctors.

\section{Acknowledgments}

None.

\section{Conflcits of interest}

The author declares there is no conflcit of interest.

\section{References}

1. Adam Augustyn, Patricia Bauer, Brian Duignan, et al. Photoelectric effect. Encyclopaedia Britannica. 1970.
Volume I Issue 2 - 2014

\author{
Nikolay Loparev \\ Department of Astrophysics and Mathematics, Private research \\ institute " Sirius A + Logos", Latvia
}

Correspondence: Nikolay Loparev, Department of Astrophysics and Mathematics, Private research institute Sirius A+ Logos, Latvia, Tel 0037I-25882550,

Email nikolaj.loparev@googlemail.com

Received: August 30, 2017| Published: September 18, 2017

2. Stoletow A. On a kind of electric current produced by ultra-violet rays. Philosophical Magazine Series. 1888;526(160):317.

3. Stoletow A. Surles courants actino-electriques au travers deTair. Comptes Rendus CVI: 1593. 1888.

4. Stoletow A. Suite des recherches actino-électriques. Comptes Rendus CVII: 91. 1888.

5. Stoletow A. Surles phénomènes actino-électriques. Comptes Rendus CVIII: 1241. 1889.

6. Stoletow A. Actin-electric studies. Journal of the Russian Physicochemical Society. 1889;21:159.

7. Stoletow A. Surles courants actino-électriques dans l'air raréfié. Journal de Physique. 1890;9(468):1-7.

8. Adam Augustyn, Patricia Bauer, Brian Duignan, et al. Planck's constant. Encyclopcedia Britannica. 2010.

9. Adam Augustyn, Patricia Bauer, Brian Duignan, et al. Photoelectric effect. Encyclopaedia Britannica. 1970.

10. Nikolay Loparev. (TOE) a Theory of Everything. International Journal of Astrophysics and Space Science. 2015;3(3):42-49.

11. Frank Neville H Robinson, Edwin Kashy Sharon, Bertsch Mc Grayne. Electromagnetism. Encyclopcedia Britannica. 2018.

12. Alan H Cook, Kenneth L Nordtvedt, James E Faller. Gravity-physics. Encyclopcedia Britannica. 2019.

13. Jonathan MW Slack, L Andrew Staehelin, Ronald A Laskey, et al. Cellbiology. Encyclopaedia Britannica. 2019. 